\title{
The role of self breath-testing devices in the Kimberley region of Western Australia
}

\author{
Rina Cercarelli, Donna Mak, Kathy Mills and Brian Jefferies
}

Copyright of Full Text rests with the original copyright owner and, except as permitted under the Copyright Act 1968, copying this copyright material is prohibited without the permission of the owner or its exclusive licensee or agent or by way of a licence from Copyright Agency Limited. For information about such licences contact Copyright Agency Limited on (02) 93947600 (ph) or (02) 93947601 (fax)

\section{Introduction}

The consumption of alcohol in the north-west region of Western Australia is high. For the year 1997/98 the State total per-capita consumption of alcohol was 10.62 litres; the per-capita consumption of the north-west region was 20.19 litres. ${ }^{1}$ High alcohol consumption has an impact on road safety. In 1998 in the Kimberley region of north-west Australia, $46 \%$ of road ratalities had a blood-alcohol concentration (BAC) exceeding $0.05 \%$, compared with $34 \%$ of road fatalities in Western Australia as a whole. ${ }^{2}$

In 1997, the Kimberley Public Health Unit conducted a sixmonth 'Kimberley crashes kill Kimberley people' campaign aimed at raising awareness of road safety issues in the Kimberley. During this campaign, a focus group of Kimberley residents identified alcohol-related road injuries as a priority area for the region.

The Kimberley Breath-Testing Project described in this paper was a pilot project to assess the role that alcohol breath-testing devices could have in reducing road fatalities and injuries in rural and remote areas of Western Australia.

Although there is little published information on their impact, the use of wall-mounted devices in metropolitan areas has been found to have a positive effect on drinking and driving behaviour as they allow drivers to determine their BAC. In a study

\section{Abstract}

Issue addressed: To examine the role that alcohol breath-testing devices in licensed premises may have in rural and remote areas of Australia.

Methods: Data to monitor the use of the wall-mounted, alcohol breath-testing devices were collected by download from the devices themselves and through survey tools for bar staff and the patrons of licensed premises. A total of 488 patrons of licensed premises were interviewed for the pre-intervention data collection and 952 patrons were interviewed post-intervention. Hand-held devices were used by 434 people at large social gatherings and all of these completed a questionnaire. Eighty-three bar staff were interviewed over the course of the project and 54 observations were made of their serving practices. A total of 695 observations of the methods of transport used by patrons leaving licensed premises were made pre-intervention and 1,095 were made postintervention. Crash data for the year preceding the installation of the devices were compared with data that covered the period of the project.

Results: Free-for-use alcohol breath-testing devices were acceptable to and supported by bar staff and people who consumed alcohol in the Kimberley region of Western Australia. Although there was no change in patrons' attitudes to drink-driving and drink-walking during the post-intervention period, there was an increase in the proportion of patrons who walked home with others and a reduction in those who travelled in vehicles as passengers. Indigenous people were less likely to intend driving, were less likely to be driving and were less likely to consider it important to stay under the legal limit when driving. The reverse, however, was true for drink walking.

Conclusions: Alcohol breath-testing devices may have a role in rural and remote areas if they are well maintained and supported by education of bar staff and the public as they provide patrons with information about bloodalcohol levels that appears to affect decisions to walk home after consuming alcohol.

Key words: Breath-testing devices, alcohol, rural and remote, drink driving, road injury.

Health Promotion Journal of Australia 2004;15:24-31

\section{So what?}

Free-for-use alcohol breath-testing devices have the potential to contribute to reduction in alcohol-related harm when used as part of a wider program. 
conducted in metropolitan Melbourne involving more than 300 interviews and observations, it was found that those respondents who had used breath-testing machines previously were more accurately able to estimate their BAC when compared with those who had never used one. ${ }^{3}$

Decisions to drive after drinking may be modified by providing drinkers with information about their blood alcohol levels. One study found that $40 \%$ of subjects were driving to licensed premises, indicating that there was a strong likelihood that they would also drive themselves home. ${ }^{4}$ Maclean et al. also found there was a belief among hotel patrons and staff that there was a responsibility on servers to help people avoid intoxication. Fixing self-testing breath analysis machines in licensed premises fulfils what many see as the licensee's responsibility, while providing patrons with the means to objectively and accurately learn about their BAC.

Mackiewicz concluded that breath-testing devices in licensed premises were effective in persuading some drivers over $0.05 \%$ not to drive. ${ }^{5}$ She found that almost a third of drivers self-testing over $0.05 \%$, who had initially intended to drive, decided not to.

Other studies have also found that breath-testing devices fixed in licensed premises had an effect in reducing drink-driving offences, although not to the same degree as was found by Mackiewicz. ${ }^{6.7}$ Haworth and Bowland's study ${ }^{6}$ had a specific aim to estimate the proportion of drinkers who intended driving home but changed their mind after finding their BAC was greater than $0.05 \%$. By interviewing those who used breath-testing machines in 10 licensed premises in Melbourne, they found $16 \%$ of drivers who had intended driving home changed their minds after finding out that their BAC was greater than $0.05 \%$.

Haworth and Bowland's study is comparable to findings in the Northern Territory where, using both interviewing and observation techniques, it was found that $20 \%$ of those tested at four premises who were over $0.05 \%$ decided not to drive after originally intending to do so.?

In a report by the NRMA-ACT Road Safety Trust, there was support for the notion that the use of breath-testing devices deterred drink-driving. ${ }^{8}$ The report states that a licensed premise manager had observed that there was an increase in the number of motor vehicles being left in the car park, which was considered to be as a direct result of breath analysis.

A survey in the ACT as reported by the NRMA-ACT Road Safety Trust found that upon installation of 'free for use' breath alcohol testers, usage rates increased. ${ }^{3}$ Over a six-month period the usage rate remained approximately the same.

There is a theme throughout the literature on breath analysis machines and their relation to drink-driving that having the machines available offers an option that is otherwise nonexistent. Sheehan registered moderate support for the introduction and development of personal breathalysers. ${ }^{9}$ Mackiewicz found acceptance of machines was high among users, with $91 \%$ feeling they should be more widely available. ${ }^{5}$

Others also register support for the provision of breath-testing devices by hotel owners and managers. ${ }^{6.10}$ Preece found that $79 \%$ of licensed premise owners surveyed responded that fixed breath-testing devices were either a very good or a good idea. ${ }^{10}$ Haworth and Bowland found that the main reasons for installing the machines were a desire to be a responsible server of alcohol or simply wanting to provide a service to customers. ${ }^{6}$

In the literature it is evident that there are perceived problems with the use of self-testing breath alcohol devices. It has been noted that a significant problem is that only $30 \%$ of users actually waited the required 10 minutes or more after drinking before they self-tested." Breakspere also pointed out that BAC may rise after testing if alcohol was still at the absorption stage. ${ }^{12}$ These problems can be countered by accompanying programs for self-testing with intensive educational resources and promotion explaining the accurate use of the machines. Problems with the accuracy of the machines can also be overcome if the machines are regularly maintained and calibrated.

Crundall noted that interviewers observed $24 \%$ of the sample apparently using the breath analysis units for competitions and amusement.' Mackiewicz found that only $6 \%$ of subjects appeared to be using the machines for this purpose. ${ }^{5}$ However, with the current technology of breath-testing devices available, it is possible to set a limit on the breath alcohol concentration a unit will display. This type of limitation will effectively defeat the competitive aspect of seeing who can get the highest $B A C$.

There is some concern about the novelty value of self-testing breath analysis units. Mackiewicz noted that quantitative data showed the machines were frequently used initially, then rates declined. ${ }^{5}$ This decline, however, remained consistent for the remaining months of the study, suggesting that there would probably always be a percentage of patrons who would use these machines.

Preece reported that $93 \%$ of the managers of licensed premises where breath-testing machines had been installed considered sales had remained the same. ${ }^{\text {io }}$

The aim of this study was therefore to examine the role that alcohol breath-testing devices in licensed premises may have in rural and remote areas of Australia. In this study, emphasis was also put on drink-walking, as $50 \%$ of Kimberley road crashes involve sober drivers and intoxicated pedestrians. ${ }^{2}$

Hand-held devices were also purchased for the project. These were to be used at large social gatherings, as much of the alcohol consumption in the Kimberley occurs outside licensed premises. As there is no published literature on the use of these devices in 
such settings, the aim of the evaluation was to explore their relevance and applicability. At present, the only breath-testing conducted in the Kimberley is done by police. It is also apparent that many indigenous people in the Kimberley do not regularly consume alcohol in licensed premises, instead preferring to drink in the open and at social gatherings. Hand-held breath testers are now sophisticated enough to be utilised in these situations. Access to hand-held breath testers by those who do not drink in licensed premises would ensure equity of access to valuable personal information and assist in the task of reducing drinkdriving.

\section{Objectives}

The objectives of the project were to:

i. Install eight wall-mounted alcohol breath-testing devices in selected licensed premises and to monitor their use over 15 months.

2. Trial the acceptability and use of hand-held alcohol breathtesting devices in at least 10 large social gatherings over 15 months in the Kimberley where a liquor license was obtained.

3. Train bar staff in the eight participating premises in responsible alcohol service using available resources.

4. Disseminate education materials regarding alcohol breathtesting and safe transport after consuming alcohol to patrons in participating premises and at large social gatherings.

5. Achieve local media coverage promoting responsible alcohol consumption and safe transport after consuming alcohol.

6. Assess the impact of the program on self-reported attitudes, drinking behaviour and transport in patrons of participating premises and large social gatherings.

7. Assess the impact of the program on observed transport behaviour from participating premises and large social gatherings.

8. Assess the impact of the program on road crash data.

\section{Method}

The study involved an evaluation of the applicability of wallmounted breath-testing devices in licensed premises in the Kimberley region of Western Australia (see Figure 1), and handheld alcohol breath-testing devices at large social gatherings. The intervention also involved safe server training for bar staff at participating licensed premises and a public education campaign. The public education campaign focused on the dangers of drink-driving and drink-walking, and gave information about how to use self breath-testing devices and where they were located in the Kimberley. Radio advertisements (in English and Kimberley Kriol) and a poster were developed with input from community organisations. The advertisement was aired
Figure 1: Device use and time of day.

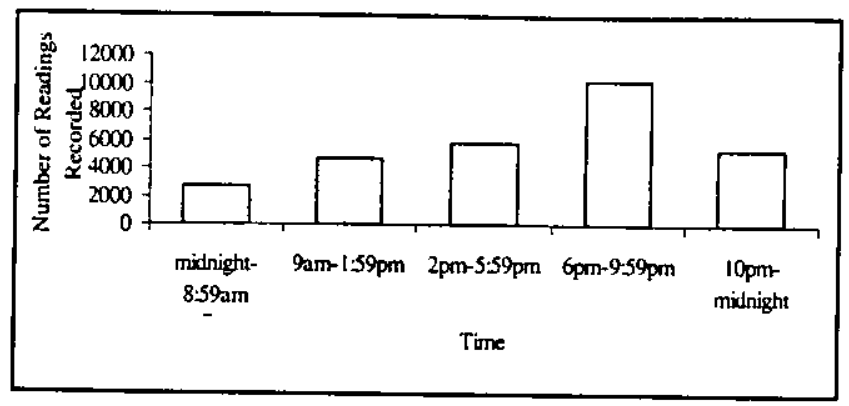

on commercial and Indigenous community radio stations. The poster was displayed in participating licensed premises, tourist bureaus and roadhouses (see Figure 2). Media releases were also used to generate publicity and educate the public using news stories in local newspapers, radio and television.

The target group of the project was Kimberley adults who consumed alcohol at participating licensed premises and large social gatherings where a liquor license had been obtained. The alcohol breath-testing devices were located at venues where people at high risk of being injured in road crashes were likely to consume alcohol. These groups included men, Indigenous people and people aged 17 to 24 years of age.

Evaluation data were collected by the following methods:

- Download of data from the alcohol breath-testing devices.

- Survey of users of hand-held devices at social events.

- Pre-intervention survey of patrons of licensed premises.

- Post-intervention survey of patrons of licensed premises.

- Post-intervention survey of staff of licensed premises.

- Post-intervention observation of staff serving practices.

- Pre-intervention observation of methods of transport from licensed premises.

- Post-intervention observation of methods of transport from licensed premises.

- Comparison of pre- and post-intervention serious/fatal road crash data and random breath-testing data.

Data to monitor the use of eight wall-mounted alcohol breath-

Figure 2: Device use and day of week.

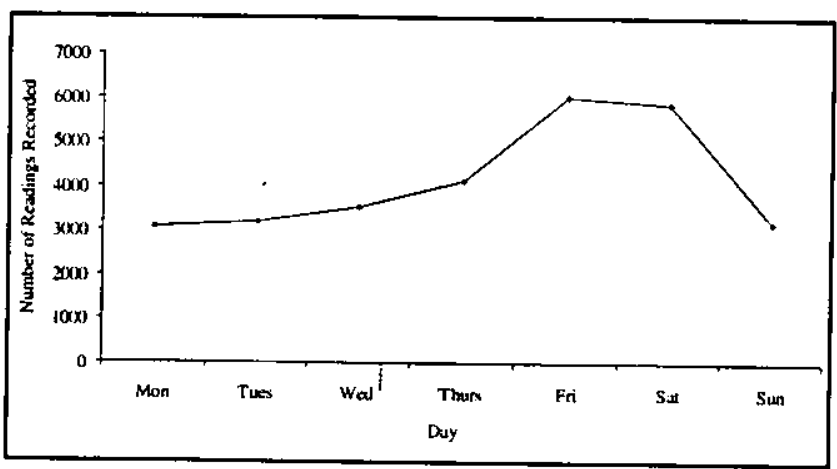


testing devices were collected by data download from the devices themselves and through interviews and observations of bar staff and the patrons of licensed premises. Pre-intervention data were collected in September, October and November 2000 , prior to installation of wall-mounted alcohol breath-testing devices in December 2000. Post-intervention data were collected at three- to four-monthly intervals from each licensed premise between January 2001 and February 2002, inclusive. Pre-planned interview and observation timetables ensured that pre- and post-intervention data for each participating premise were collected on the same day of the week and at the same time of day. Data collectors always informed bar staff of their presence at the licensed premise; however, it was unlikely that this would have affected the behaviour of bar staff as data collectors located themselves in unobtrusive positions, outside the direct view of bar staff, when conducting observations. Data were collected by a health promotion officer employed by the Kimberley Public Health Unit, an Indigenous research assistant, three medical students and the second author (DM). Standardised interview and observation proformas were used and all data collectors were trained by the health promotion officer to ensure validity of the data collection process.

Data about hand-held devices were collected by interviewing each person who used one of these devices. Interviews were conducted by a health promotion officer employed by the Kimberley Public Health Unit, an Indigenous research assistant, three medical students and the second author (DM). A standardised interview proforma was used and all interviewers were trained by the health promotion officer to ensure validity of the data collection process.

Road crash and random breath-testing data (collected by WA Police Service) for the 11 months preceding the installation of the devices (1 January 2000-30 November 2000) were compared with data that covered the period of the project (1 December 2000-28 February 2002). A serious/fatal road crash was defined as a road crash where at least one person was hospitalised and/or died as a result of the crash. Crashes were defined as alcohol-related where at least one person involved had a BAC over $0.05 \%$, as determined by police through a blood or breath test.

\section{Results}

Wall-mounted alcohol breath-testing devices were installed in a total of eight licensed premises (seven hotels and one not-forprofit sporting club) located in all six Kimberley towns. A total of 488 patrons of licensed premises were interviewed for the pre-intervention data collection and 952 patrons were interviewed post-intervention. Four hundred and thirty-six patrons declined to be interviewed in the pre- and post-surveys. The demographic characteristics of interviewees are detailed
Table 1: Demographic characteristics of interviewees.

\begin{tabular}{lccc}
\hline Characteristic & $\begin{array}{c}\text { Pre- } \\
\text { intervention } \\
n=488(\%)\end{array}$ & $\begin{array}{c}\text { Post- } \\
\mathbf{n}=952(\%)\end{array}$ & Total \\
\hline Male & $367(75)$ & $711(75)$ & $1,078(75)$ \\
Fernale & $121(25)$ & $240(25)$ & $361(25)$ \\
Missing data & 0 & $1(0)$ & $1(0)$ \\
\hline Indigenous & $139(29)$ & $311(33)$ & $450(31)$ \\
Non-Indigenous & $349(71)$ & $636(67)$ & $985(69)$ \\
Missing data & $0(0)$ & $5(0)$ & $5(0)$ \\
\hline Age group & & & \\
Less than 18 years & $1(0)$ & $1(0)$ & $2(0)$ \\
18-24 & $94(19)$ & $190(20)$ & $284(20)$ \\
$25-29$ & $104(21)$ & $232(25)$ & $336(23)$ \\
$30-39$ & $152(31)$ & $298(31)$ & $450(31)$ \\
$40-49$ & $75(14)$ & $133(14)$ & $208(14)$ \\
$50-59$ & $47(10)$ & $65(7)$ & $112(8)$ \\
$60-69$ & $11(2)$ & $23(2)$ & $34(2)$ \\
70 years or over & $4(1)$ & $6(1)$ & $10(1)$ \\
Missing data & $0(0)$ & $4(0)$ & $4(0)$ \\
\hline
\end{tabular}

in Table 1. Eighty-three bar staff were interviewed over the course of the project and 54 observations were made of their serving practices. None of the bar staff declined being interviewed. A total of 695 observations of the methods of transport used by patrons leaving licensed premises were made pre-intervention and 1,010 were made post-intervention. The hand-held devices were used by 434 people at large social gatherings, including horse races, rodeos, football games and music concerts, and all of these people completed a questionnaire.

\section{Use of wall-mounted alcohol breath-testing devices}

A total of 28,989 readings were downloaded from the devices during the period of the project. The devices were most often used between the hours of $6 \mathrm{pm}$ and $9.59 \mathrm{pm}$ (see Figure 1) and on the days Friday and Saturday (see Figure 2). There was a consistent decline in the utilisation of the wall-mounted devices over time (see Figure 3).

Thirty-seven per cent of staff said that they often saw the device being misused, while $16 \%$ said that they never saw it being

Figure 3: Overall use of the alcohol breath-testing devices over the 15-month period of the project.

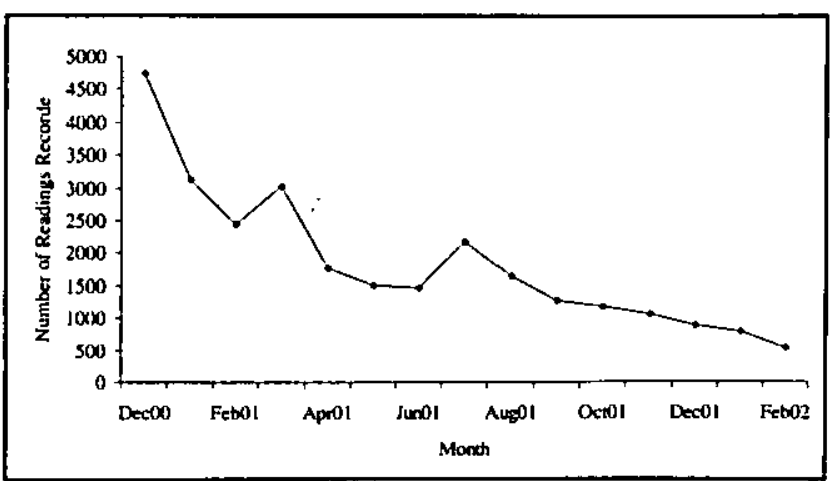


misused. The majority of staff ( $72 \%)$ thought that the devices encouraged patrons to be more aware of their alcohol consumption.

\section{Technical and logistical difficulties}

The devices failed a total of eight times at four premises. One incident was due to a power failure and the other seven were probably due to misuse (patrons blowing alcohol into the device to get a high reading). Liquid was frequently detected in the valve of the devices due to alcohol being blown through the straw into the port, which led to the valve becoming stuck. This was rectified by cleaning with a pipe cleaner.

While the devices auto-calibrated they also needed manual calibration every six months. There were difficulties in getting bar managers to dismount the devices, pack them securely in bubble-wrap and send them away for calibration. In addition, some devices were not immediately replaced on the wall after being calibrated, which resulted in them being unavailable for use for periods of time.

\section{Findings of the observations of staff serving practices}

In $96 \%$ of observations the bar staff were never seen encouraging use of the alcohol breath-testing device. In $53 \%$ of observations staff were seen to serve a patron whom the observer judged to be intoxicated, and this occurred more than once during $40 \%$ of observations. On only one occasion (2\%) were staff seen serving a patron whom the observer judged to be under-age.

All of the licensed premises had low-alcohol drinks and these were promoted in $92 \%$ of observations. All of the licensed premises had soft drinks and/or water available and served food. Two of the eight licensed premises were consistently recorded as displaying information about safe serving practices.
Figure 4: Self-reported use or intention to use alcohol breathtesting devices, Jan 2001-Feb 2002, by Indigenous status and age group, $n=952$.

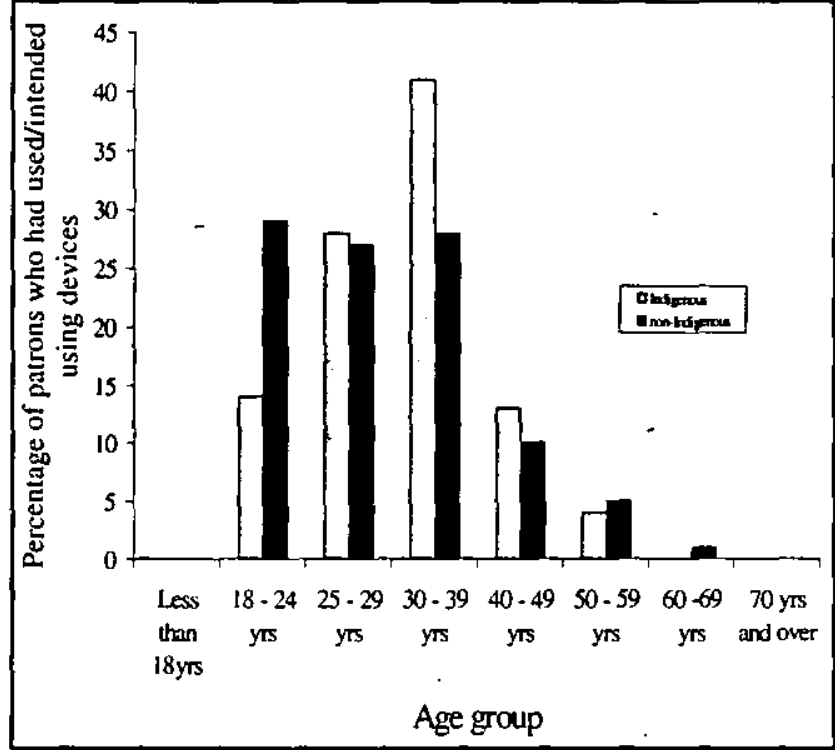

\section{Findings of the pre- and post-intervention surveys of patrons of licensed premises}

Findings of the pre- and post-intervention surveys of patrons at licensed premises are summarised in Table 2 . Although $67 \%$ of patrons in the pre-intervention phase said they would use an alcohol breath-testing device if one were available, in the postintervention phase only $37 \%$ said they had used or intended using the device that day/night. Younger patrons were more likely to report use of, or intent to use, an alcohol breath-testing device (see Figure 4). The majority of patrons who reported not using or not intending to use the device said they did not feel the need to. Patrons supported this by quoting the number of

Table 2: Findings of pre- and post-intervention surveys of patrons.

\begin{tabular}{|c|c|c|c|}
\hline Survey question & $\begin{array}{l}\text { Pre-intervention } \\
n=\mathbf{4 8 8}(\%)\end{array}$ & $\begin{array}{c}\text { Post-intervention } \\
n=952(\%)\end{array}$ & $\chi^{2}, d f, p$ \\
\hline Use or intention to use alcohol breath-testing device & $326(67)$ & $355(37)$ & $114.5,1,0.00$ \\
\hline How do you know when you have reached the legal limit? & & & $9.7,2,0.01$ \\
\hline The way I feel & $220(45)$ & $363(39)$ & \\
\hline Counting drinks & $156(32)$ & $303(33)$ & \\
\hline Other response & $112(23)$ & $286(28)$ & \\
\hline It is very important to stay under the legal limit $(0.05 \%)$ when driving & $361(74)$ & $654(69)$ & $4.3,1,0.04$ \\
\hline There is a lot of risk in driving if over the legal limit $(0.05 \%)$ & $376(77)$ & $733(77)$ & $0.0,1,0.98$ \\
\hline I would never consume alcohol and drive & $263(54)$ & $496(52)$ & $0.0,1,0.90$ \\
\hline It is very important to stay under the legal limit $(0.05 \%)$ when walking & $293(60)$ & $607(63)$ & $1.9,1,0.17$ \\
\hline There is a lot of risk in walking if over the legal limit $(0.05 \%)$ & $146(30)$ & $269(28)$ & $0.4,1,0.51$ \\
\hline Intended method of transport to get home & & & $38.2,4,0.00$ \\
\hline Drive & $98(20)$ & $188(20)$ & \\
\hline Passenger (taxi or private vehicle) & $176(36)$ & $284(30)$ & \\
\hline Walk alone & $127(26)$ & $179(18)$ & \\
\hline Walk with others & $73(15)$ & $198(21)$ & \\
\hline Other response & $14(3)$ & $93(10)$ & \\
\hline
\end{tabular}


drinks they had consumed, saying they did not intend staying at the hotel long or saying they knew their own limit. Ninety per cent of patrons agreed with the devices being available.

There was a significant overall decrease, from $45 \%$ to $39 \%$, in the proportion of patrons reporting that they judged whether they had reached the legal limit by the way they felt $\left(\chi^{2}=6.5\right.$, $d f=1, p=0.01$ ).

As shown in Table 2, there was no significant change in patrons' beliefs and attitudes about driving or walking with a blood alcohol level over $0.05 \%$. Non-Indigenous patrons were more concerned than Indigenous patrons about staying under the limit when driving. This did not change post-intervention. Overall, $60 \%$ (270/450) of Indigenous people and $76 \%$ (749/985) of nonIndigenous people thought it was very important $\left(\chi^{2}=38.6\right.$, $d f=1, p=0.00$ ). By contrast, Indigenous patrons were much more concerned than non-Indigenous patrons about staying under the limit when walking and about the risks of walking with a $B A C$ over $0.05 \%$. This did not change post-intervention. Overall, 33\% (150/450) of Indigenous people and 13\% (128/ 985) of non-Indigenous people thought it was very important to stay under the limit when walking $\left(\chi^{2}=81.8, d f=1, p=0.00\right)$, and $45 \%$ (204/450) of Indigenous people and 21\% (207/985) of non-Indigenous people thought walking with a BAC over $0.05 \%$ was very risky $\left(\chi^{2}=89.4, d f=1, p=0.00\right)$.

There was no change in the proportion of patrons who intended to drive home (see Table 2), however, the proportion who intended to walk home alone decreased from $26 \%$ to $18 \%$ $\left(\chi^{2}=9.4, d f=1, p=0.00\right)$ and the proportion intending to walk home with others increased from $15 \%$ to $21 \%\left(\chi^{2}=7.7, d f=1\right.$, $p=0.01$ ).

Findings of the pre- and post-intervention observations regarding transport from licensed premises

As shown in Table 3, there was no change in the proportion of patrons observed driving home (either alone or with passengers) or walking home alone. The proportion of patrons walking home with others increased from $32 \%$ to $40 \%\left(\chi^{2}=12.9, d f=1\right.$, $p=0.00$ ), and the proportion who left as a passenger in a private

Table 3: Findings of pre- and post-intervention observations of patrons' transport from licensed premises.

\begin{tabular}{lcc}
\hline Method of transport & $\begin{array}{c}\text { Pre- } \\
\text { intervention } \\
\mathrm{n}=695(\%)\end{array}$ & $\begin{array}{c}\text { Post- } \\
\text { intervention } \\
\mathrm{n}=1,010(\%)\end{array}$ \\
$\chi^{2}, d f, \rho$ \\
\hline Drove alone & $76(11)$ & $132(13)$ \\
Drove with passengers & $77(11)$ & $98(10)$ \\
Passenger in private vehicle & $146(21)$ & $106(11)$ \\
Passenger in taxi & $63(9)$ & $58(6)$ \\
Walked alone & $104(15)$ & $185(18)$ \\
Walked with others & $222(32)$ & $409(40)$ \\
Other & $7(1)$ & $22(2)$ \\
Total & $695(100)$ & $1,010(100)$ \\
\hline
\end{tabular}

vehicle decreased from $21 \%$ to $11 \%\left(\chi^{2}=36.1, d f=1, p=0.00\right)$. These trends were particularly marked among Indigenous patrons (see figure 5). Figure 5 also highlights the differences in transport methods between Indigenous and non-Indigenous patrons, with non-Indigenous patrons being much more likely than Indigenous patrons to be driving, and Indigenous patrons being much more likely than non-Indigenous patrons to be walking.

Findings of the surveys for people using the hand-held devices at large social events

Of people using the hand-held devices, $66 \%$ were male and $34 \%$ were female. Fifteen per cent were Indigenous and $85 \%$ were non-Indigenous. Seventeen per cent were aged 18-24 years, $23 \%$ were $25-29$ years, $25 \%$ were $30-39$ years, $14 \%$ were $40-49$ years, $15 \%$ were $50-59$ years and $6 \%$ were 60 years or older. Sixty-nine per cent identified themselves as residents of the Kimberley region, $25 \%$ were from other areas within Australia and $6 \%$ were from overseas.

Forty per cent (172/428) of people intended getting home as passengers in private vehicles, while 30\% (129/428) intended driving home. Non-Indigenous people were nearly twice as likely to intend driving home as Indigenous people (33\% compared with $16 \%, \chi^{2}=7.8, d f=1, p=0.005$ ). Indigenous people were more likely to intend walking home alone. Eighteen per cent of Indigenous people intended walking home alone compared with $4 \%$ of non-Indigenous people $\left(\chi^{2}=14.0, d f=1, p=0.001\right)$.

Sixty-seven per cent of those who intended driving and $93 \%$ of those who intended walking home had consumed three alcoholic drinks or more. Thirty-six per cent of people who said they intended driving and $75 \%$ of people who intended walking home recorded a BAC over $0.05 \%$.

Figure 5: Observed methods of transport from licensed premises, by Indigenous status, $n=1705$.

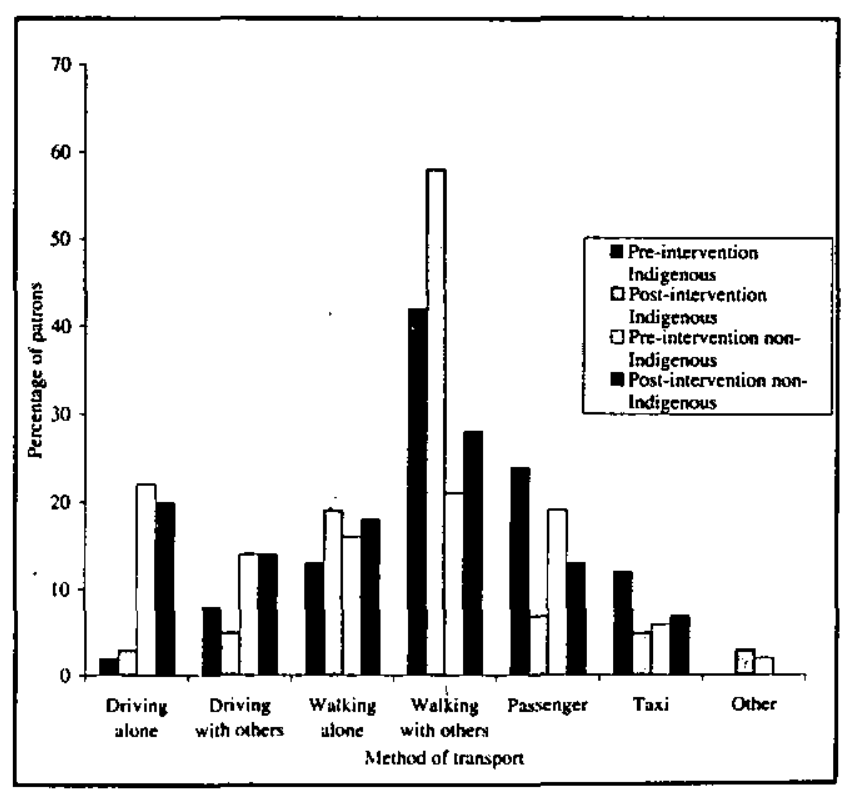


Ninety-six per cent of participants said they agreed about making alcohol breath-testing devices more widely available at such events. Project staff observed people changing their minds about driving home based on their BAC reading, for example, some people called a taxi, others asked a friend (who had not been drinking or whose BAC was under the legal limit) to drive them home.

It was originally intended that security staff and Indigenous wardens at the events would be trained to use the devices, to enable them to assist the project officer and research assistant. However, it was found that this was impractical as these staff were fully occupied with maintaining security at the venues.

\section{Findings of the comparison of pre- and post- intervention crash data}

In the 11 months preceding the alcohol breath-testing device project there were 19 road crashes that resulted in fatalities or serious injury, of which $53 \%$ were confirmed as involving alcohol. During the 15-month period of the project, there were 25 road crashes that resulted in fatalities or serious injury, of which $56 \%$ were confirmed as involving alcohol.

Two per cent of random breath-tests (RBTs) were positive preintervention compared with $3 \%$ post-intervention.

\section{Discussion}

This paper highlights several important considerations in assessing self breath-testing monitors in the Kimberley region. The technical and logistical difficulties experienced in this study are not uncommon with breath-testing devices; however, the study highlighted the difficulties of maintaining calibration levels of the devices, particularly in a remote area. Previous research has shown the importance of wall-mounted breath-testing devices being regularly calibrated. ${ }^{13}$

The remoteness of the Kimberley region not only made it difficult to have the devices regularly calibrated (the devices were sent to Perth, more than 2,000 kilometres away, for calibration), but also highlighted the difficulties in establishing a health promotion intervention in a remote area. Challenges such as with calibration, surveying people in six towns up to 1,000 kilometres apart, and cross-cultural communication were all experienced in this study.

The intervention appeared to have little effect on road crashes in the Kimberley region of Western Australia, although this is not entirely unexpected because of the many factors that have an impact on road crash rates. Road crashes are caused by many factors (not just alcohol), including speed, driver fatigue, the road environment, and vehicle defects. It is unlikely that a change in crash rates could be detected over such a relatively small period of time. Better indicators of the effect of the intervention in the short term are through a combination of observational and attitudinal measures to assess the intervention's impact on drivers' and pedestrians' decisions to drive and/or walk. It is also these that can inform a health promotion program.

The study showed that free-for-use alcohol breath-testing devices were acceptable to and supported by bar staff and people who consumed alcohol in the Kimberley region. After the project, one sporting club kept the alcohol breath-testing device as a service for its members and staff. There was also demand from managing registrars for hand-held devices at social events where an occasional liquor licence was applied for. However, after the project's completion we were unable to meet these requests due to limited availability of staff or volunteers trained to manage the devices at the time these social events were scheduled (mainly weekends and at night).

There were also instances where the monitors were damaged. This might be evidence of a more general hostile attitude to the intrusion of enforcement against drink-driving, and the perceptions of patrons about how these monitors fit with general road safety strategies needs further investigation.

Although there was no change in patrons' attitudes to drinkdriving and drink-walking during the post-intervention period, there was an increase in the proportion of patrons who walked home with others and a reduction in those who travelled in vehicles as passengers. This is a positive finding supporting the intervention. However, more specifically, an important finding of the study was the differences in transport methods between Indigenous and non-Indigenous people. Indigenous people were less likely to intend driving (see hand-held results), were less likely to be driving (see observation of transport results), and were less likely to consider it important to stay under the legal limit when driving (see patron survey results). The reverse, however, was true for drink-walking.

The above finding of a shift in behaviour but not attitude is interesting. On one hand this could indicate a weakness of attitude measures - and highlight the importance of observational methods in assessing the effectiveness of monitors. The unreliability of attitude measures is shown where people's attitudes to the 'importance' of staying under the legal limit while driving decreased. This could be taken as worsening post-intervention, except that it might be accounted for by the finding that more people were willing to walk home with others after the intervention (a positive outcome). There might be a general shift in cognitive focus to walking rather than driving and thus the finding of less 'importance' attached to being under the limit while driving (or, that is, anything to do with driving generally) could be an artifact of the post-intervention shift to walking.

Given the complexity of measuring attitudes, observational methods are preferred in future. At large social events where hand-held devices were available, project staff observed people changing their minds about driving home, based on their BAC 
reading; however, this is only anecdotal and more rigorous observations should be employed in future. More importantly, the observations that were made were of those doing the 'right thing' and observations need to be made of patrons where there was no change in safer transport.

The main role that the devices have appears to be in raising awareness. Future observations will show whether they are a useful dimension of an overall multi-strategic program to reduce drink-driving.

\section{Conclusion}

If alcohol breath-testing devices are to have a role in rural and remote areas they need to be well maintained and supported by education of bar staff and the public. The breath-testing devices provided patrons with information about blood alcohol levels that appeared to affect decisions to walk home after consuming alcohol. Walking home rather than driving is a positive strategy. It was also important that bar staff were knowledgeable in the information they provided, and that patrons received supporting information to affect their decision to drive or walk from broader education initiatives. The study showed that usage of the devices decreased towards the end of the study as has been seen in other studies. ${ }^{5}$ Therefore, continued publicity and education about the devices directed to the public is important to maintain high levels of usage and to ensure they are not seen as a novelty only.

\section{Acknowledgements}

The authors would like to acknowledge Healthway for funding this project. The following people and organisations contributed to the project: Louise Spehr, Osman Bin Omar, Nicole Hall, Ian McWhirter, Deepak Cheriachen, Jodie Auster, Margi D'Antoine, Garl Garl Walbu, Lindsay Bennett, Andrew Amor, Milliya Rumurra, Elizabeth Topp, Bill Young, Barry Newell, Sonya Nixon, WAfm, Northwest Radio, and Warringarri Radio.
Drivecheck Pty Ltd leased the wall-mounted alcohol breathtesting devices for the project at a much reduced cost. Wesfarmers Transport provided free freight for all eight devices to their six locations throughout the Kimberley, both at the time of installation and when the devices needed to be returned for calibration or repair. Kimberley Regional Service Providers also supported the project by providing travel costs for Vince Ceorge from Drivecheck Pty Ltd to visit the Kimberley for the installation of the devices, and who provided back-up maintenance.

The authors would also like to thank the licensees of the eight licensed premises around the Kimberley who supported the project by having an alcohol breath-testing device placed in their premises.

\section{References}

1. Alcohol Related Harm in Westem Australia. Perth (WA): Drug and Alcohol Office and Department of Health, Western Australia; 2002. Occasional Paper No.: 7.

2. Jefferies B. Personal communication; 2001.

3. Mackiewicz $G$. The efficacy and educative value of coin-operated breath testers Proceedings of the 11th intemational Conference on Alcohol, Drugs and Traffic Safety; 1989 October 24-27; Chicago, Illinois. Bud MW, editor. Chicago: Nationa Safety Council, 1990.

4. Maclean S, Wood L, Montgomery I, Davidson J, Jones M. Promotion of responsible drinking in hotels. Drug Alcohol Rev 1994; 13:247-55.

5. Mackiewicz C. The Efficacy and Educative Value of Coin-Operated Breath Testers Melbourne (VIC): Road Traffic Authority; 1988.

6. Haworth N, Bowland L. Estimation of Benefit-Cost Ratios for Coin-Operated Breathtesting. Melbourne (VIC): Monash University Accident Research Centre; 1995.

7. Crundall I. A Trial of Coin-Operated Breathalysers in the Northern Territory, Darwin (NT): Alcohol and Other Orug Services, Territory Health Services; 1996.

8. Breath Alcohol Testing. First Report. Canberra (ACT): NRMA-ACT Road Safery Trust; 1996.

9. Sheehan M. Alcohol Controls and Drink Driving: The Social Context. Canberra (ACT): Federal Office of Road Safety; 1994. Catalogue No.: CR142.

10. Preece R. The promotion and use of public breath testing devices. Proceedings of the 13th intemational Conference on Alcohol, Drugs and Traffic Safety; 1995 August 13.18; Adelaide, Australia. Kloeden CN, McLean AJ, editors. Adelaide: NHMRC Road Accident Research Unit; 1995.

11. Lyttle I, South D. Public breath testing. Proceedings of the Australasian Drink Drive Conference; 1993 November 22-23; Melboume, Australia 1994.

12. Breakspere I. Evaluation of Public Breath Alcohol Devices. Sydney (NSW): School of Chemical \& Earth Sciences, New South Wales Institute of Technology; 1994.

13. Hay C. Cercareili LR. An Evaluation of Coin Operated Breath Analysers installed in Licensed Premises in the Perth Metropolitan Avea. Perth (WA): Injury Research Centre, The University of Western Australia; 2002.

\section{Authors}

Rina Cercarelli, Injury Research Centre, School of Population Health, University of Western Australia

Donna Mak, Kimberley Public Health Unit, Western Australia, and School of Population Health, University of Western Australia

Kathy Mills, Kimberley Public Health Unit, Western Australia

Brian Jefferies, Western Australia Police Service

Correspondence

Dr Rina Cercarelli, Injury Research Centre, School of Population Health, University of Western Australia, 35 Stirling Highway,

Crawley, Western Australia 6009. Tel: (08) 9380 1306; fax: (08) 9380 1199; e-mail: rina@dph.uwa.edu.au 